Rather than being ready for an assessment of its effectiveness and cost-effectiveness in non-experimental settings, as Thornicroft \& Susser argue, cognitive therapy may be in the process of meeting the fate of an earlier treatment for schizophrenia where advocacy preceded rigorous evaluation - insulin coma.

Curtis, D. (1999) Intensive cognitive behaviour therapy for chronic schizophrenia. Specific effect of cognitive behaviour therapy for schizophrenia is not proved (letter). British Medical Journal, 318, 331.

Drury, V., Birchwood, M., Cochrane, R., et al (1996) Cognitive therapy and recovery from acute psychosis: a controlled trial. I. Impact on psychotic symptoms. British Journal of Psychiatry, 169, 593-601.

Kuipers, E., Garety, P., Fowler, D., et al (1997) London-East Anglia randomised controlled trial of cognitive-behavioural therapy for psychosis. I. Effects of the treatment phase. British Journal of Psychiatry, 17I, 319-327.

Sensky, T., Turkington, D., Kingdon, D., et al (2000) A randomised controlled trial of cognitive-behavioural therapy for persistent symptoms in schizophrenia resistant to medication. Archives of General Psychiatry, 57, 165-172.

Tarrier, N., Yusupoff, L., Kinney, C., et al (1998) Randomised controlled trial of intensive cognitive behaviour therapy for patients with some schizophrenia. British Medical Journal, 317, 303-307.

Thornicroft, G. \& Susser, E. (200I) Evidence-based psychotherapeutic interventions in the community care of schizophrenia. British Journal of Psychiatry, 178, 2-4.

P. J. McKenna Fulbourn Hospital, Cambridge CBI 5EF

\section{No long-term benefit for cognitive therapy in acute psychosis: a type II error}

Drury et al (2000) reported no significant difference in relapse rates, positive symptoms or insight between a cognitive therapy group and a recreational activities and support group of patients who had an acute episode of a non-affective psychosis. This 5-year outcome study assessed 34 out of an original cohort of 40 patients.

Working on the basis of small trials having a large type II error, the group size for each group can be estimated. If the anticipated mean response in one group is $\mu_{1}$ and the standard deviation is $\sigma$, to show a significant result the mean relapse of one group can be estimated at $2\left(\mu_{1}\right)$ and the standard deviation can be estimated at 1.5 $(\sigma)$. The estimated difference between the groups $(\delta)$ can be set at $0.5\left(\mu_{2}-\mu_{1}\right)$. A formula to calculate the number $(n)$ in each group (Pocock, 1983: 127-128) can be used as follows:

$$
n=\frac{2 \sigma^{2}}{\left(\mu_{1}-\mu_{2}\right)^{2}} \times f(\alpha, \beta)
$$

The $\alpha$ (type I error) is by convention set at 0.05 , and the $\beta$ (type II error) can be set at 0.2 . The power of finding a true result $(1-\beta)$ will therefore be 0.8 or $80 \%$ and, by using a statistical table, $f(\alpha, \beta)$ is 7.9 . Therefore, $n$ can be calculated as

$$
\frac{2 \times 1.5^{2}}{0.5^{2}} \times 7.9=142
$$

patients in each group.

It would therefore take a very large sample to prove the null hypothesis in the above hypothetical estimate. In the study by Drury et al (2000), it would be misleading to extrapolate that there was no long-term benefit of using cognitive therapy in schizophrenia in terms of relapse. Larger studies are needed in this rapidly evolving area.

Drury, V., Birchwood, M. \& Cochrane, R. (2000) Cognitive therapy and recovery from acute psychosis: a controlled trial. 3. Five-year follow-up. British journal of Psychiatry, 177, 8-14.

Pocock, S. (1983) Clinical Trials: A Practical Approach Chichester: John Wiley \& Sons.

K. Marlowe Lambeth Mental Health Services, South London and Maudsley NHS Trust, 108 Landor Road, London SW9 9NT

\section{Seasonal variation in suicides: hidden not vanished}

Yip et al (2000) demonstrated that, in England, the seasonal variation in suicide rates in the 1980s and 1990s decreased considerably when compared with that in the 1960s and 1970s. From monthly suicide frequencies, they concluded that current data hardly show any seasonal effects on suicide rates, and they predicted that seasonal variation in suicide rates would disappear completely in the years to come.

Although we fully agree with Yip et al (and several other authors) that there is a global decline in the amplitude of seasonal variation in suicide rate, we do not agree with the conclusion that seasonal influences are beginning to fade away. We came to this conclusion by a recent study of train suicides (i.e. suicide by jumping before a moving train) in The Netherlands (van Houwelingen \& Beersma, 2001). In this study $(n=30)$ we confirmed the absence of a seasonal pattern in suicide rates as observed in 28-day intervals. We did, however, observe a strong seasonal influence on 24hour patterns. Whereas the winter season showed two daily peaks in suicide rates, at around 9-11 am and 7-10 pm, the summer season revealed one major peak around 12 $4 \mathrm{pm}$ and a smaller peak shortly before midnight. The timing of the major summer peak is in the trough between the two winter peaks.

This more subtle influence of time of year on suicide rates adds a different dimension to what has been considered seasonality in suicidal behaviour and may generate new ideas concerning relevant factors involved. In train suicide data, seasonal influences are clearly present. This may also be true of other methods of suicide. In order to see this, time of day and time of year have to be taken into account simultaneously.

van Houwelingen, C. A. J. \& Beersma, D. G. M. (200I) Seasonal changes in 24-h patterns of suicide rates: a study on train suicides in The Netherlands. Journal of Affective Disorders, in press.

Yip, P. S. F., Chao, A. \& Chiu, C. W. F. (2000) Seasona variation in suicides: diminished or vanished. Experience from England and Wales, 1982-1996. British Journal of Psychiatry, 177, 366-369.

C. A. J. van Houwelingen GGz Eindhoven, $\mathrm{PO}$ Box 909, 5600 AX Eindhoven, The Netherlands

D. G. M. Beersma Department of Psychiatry and Zoological Laboratory, University of Groningen, PO Box 14,9700 AA Haren, The Netherlands

\section{Soviet-style psychiatry is alive and well in the People's Republic}

The involuntary committal to psychiatric institutions of political dissenters has long been associated with the abuses of psychiatric practice perpetrated in the former Soviet Union. The detention of dissenters may be based upon psychiatric judgement but political factors are relevant when such abuse becomes widespread. International concern has been growing following the decision of the Chinese Government to outlaw the practice of Falun Gong and forcibly to assign psychiatric treatment to practitioners of this meditative discipline. Falun Gong, also known as Falun Dafa, 
was banned in July 1999 following its declaration by Chinese authorities as a religious cult in passive rebellion to the Government. Falun Gong is a traditional spiritual discipline that has its roots in ancient Chinese culture. It draws on Buddhism, Taoism and the traditional Chinese doctrine of Qigong and involves gentle exercise and meditation. The crackdown against even private practice of the meditative exercise has resulted in over 600 detentions in psychiatric hospitals, where sedative and antipsychotic medications have been routinely and forcibly administered, along with electroconvulsive therapy (Ahmad, 2000) in an attempt to make practitioners renounce their beliefs.
Amnesty International is concerned that such forced incarceration will escalate as the authorities attempt to discredit Falun Gong and to brand its practitioners as 'crazy'. The spurious diagnosis of 'Qigonginduced mental disorder' has even been described by some Chinese psychiatrists who claim obsessional symptoms, paranoid ideation, anxiety and depression as its core features. Other human rights violations, such as torture and ill treatment in custody, have resulted in a mounting death toll, currently standing at 77 according to Amnesty International (2001).

Attempts have been made this year by the American Psychiatric Association's Committee on the Abuse of Psychiatry and Psychiatrists to encourage the World Psychiatric Association to undertake a review of these alleged wrongful detentions. The failure of even a proportion of Chinese psychiatrists to function within an articulated ethical framework along generally acknowledged international standards diminishes all of us practising in the arena of mental health.

Ahmad, K. (2000) International concern grows over psychiatric abuses in China. Lancet, 356, 920.

Amnesty International (200I) News review - China crackdown. Amnesty, 105, January/February, II.

D. Lyons Old Age Directorate, The Maudsley Hospital, Denmark Hill, London SE5 8AZ

\section{One hundred years ago}

\section{The role of consanguinity in the etiology of epilepsy, hysteria, idiocy, and imbecility}

A contribution of interest on the above subject appears in a recent Thèse de Paris (1900) by Dr. Theophile Gillet of Paris, dealing with the results of consanguineous marriages in relation to certain neuroses and psychoses. Dr. Rilliet and Dr. Barthez in their classical "Treatise on the Diseases of Children" (1859) had stated that the results of consanguinity of parents were as follows. First, fewer births; secondly, more miscarriages and still births than the average; thirdly, weakness (physical and moral) of the surviving children; fourthly, a special tendency in the offspring to diseases of the nervous system, such as epilepsy, idiocy and imbecility, deaf-mutism, and local cerebral palsies; and lastly, a special proclivity in the offspring to tuberculous degeneracy. It has since been stated that among the more frequent results of consanguinity in the parents are such abnormalities as albinism, deaf-mutism, and retinitis pigmentosa in the offspring, even in cases where but one parent showed the specific morbid taint. The observations of Dr. Gillet were made at the Bicêtre during 11 years (from 1889 to 1900), during which period 1228 children were under care and treatment. Inquiries were also made into the histories of 425 girl patients at the Fondation Vallée, Paris, an institution for children suffering from nervous diseases. The total number of cases investigated was, therefore, 1653. Inquiries into the family histories of these patients elicited the fact that there were 45 instances of consanguineous marriage in the parents. These $\mathbf{4 5}$ families were minutely studied, with the result that the offspring of these families taken en bloc showed 19 cases of idiocy, 14 of epilepsy (idiopathic or symptomatic), eight of imbecility, three of hydrocephalus, one of chorea, and one of idiocy [sic], a total of 46 grave neuroses and cerebral defects. The relative degrees of consanguinity were as follows. In 28 instances the father and mother were first cousins, in nine they were the children of first cousins, in seven instances they were cousins of the third, fourth, and fifth degree, and in one case uncle and niece. Inquiry into the condition of their children during infancy revealed the fact that convulsions and meningitis were notably prevalent, while idiocy or imbecility and chorea were also found to prevail in an abnormally high degree. Taking the total of all the surviving children of these consanguineous marriages it appeared that 2.7 per cent of them suffered from idiocy, epilepsy, imbecility, hysteria, or other grave cerebral disorders - a proportion very much larger than that generally present among the offspring of those in the same rank of life but who had not contracted consanguineous marriages.

\section{REFERENCE}

Lancet, 22 December 1900, 1822-1823.

Researched by Henry Rollin, Emeritus Consultant Psychiatrist, Horton Hospital, Epsom, Surrey 